\title{
Xeroderma Pigmentosum in an African-American
}

\author{
Ryan K. Orosco ${ }^{a}$ Timothy Wang ${ }^{b}$ Patrick J. Byrne ${ }^{a}$ \\ Departments of a Otolaryngology-Head and Neck Surgery and ${ }^{b}$ Dermatology, Johns Hopkins Hospital, \\ Baltimore, Md., USA
}

\section{Key Words}

African-American · Cutaneous neoplasm $\cdot$ Xeroderma pigmentosum

\begin{abstract}
Aims: To describe a case of xeroderma pigmentosum (XP) in a middle-aged African-American woman, and to review pertinent literature on this rare clinical scenario. Methods: Case report and English literature review related to XP in black patients. Results: A 34-year-old African-American woman diagnosed with XP with first cutaneous squamous cell carcinoma (SCC) at age 23 years progressed to develop additional SCC, basal cell carcinomas, and melanoma in situ. She was treated with sun avoidance and protection and required multiple excisions. Conclusions: We report a case of XP with a rare presentation in an African-American with onset of $\mathrm{Cu}$ taneous neoplasm in her third decade. Severe photosensitivity and common malignancy seen in XP patients necessitate frequent surveillance with a low threshold for intervention. This case highlights the ability of XP to present in this demographic with a diverse spectrum of malignancies, and a potentially prolonged clinical course.
\end{abstract}

Copyright $\odot 2011$ S. Karger AG, Basel (c) 2011 S. Karger AG, Basel

0301-1569/11/0733-0162\$38.00/0

Fax +4161306 1234

E-Mail karger@karger.ch

www.karger.com
Accessible online at:

www.karger.com/orl

\section{Introduction}

Xeroderma pigmentosum (XP) is a rare autosomal recessive disease resulting from mutations in genes responsible for DNA repair. These mutations cause patients severe ultraviolet (UV) photosensitivity and a propensity towards early development of cutaneous malignancies, which occur almost exclusively in sun-exposed regions. Multiple suspect mutations, patient demographics, severity of UV exposure, and varied healthcare environments contribute to the spectrum of disease severity reported in XP patients. Experience with this disease in the African black population has been described, but published experience in African-Americans is lacking.

\section{Case Report}

A 34-year-old African-American woman was initially seen for a full skin examination in our practice, with persistent skin dryness, dyspigmentation, and multiple cutaneous lesions. The diagnosis of XP had been made due to her characteristic skin changes and bilateral corneal scarring. She reported skin problems since age 6 years. She wore sunscreen, but did not practice sun avoidance. She had no hair loss or neurological problems. Past medical history was otherwise remarkable only for cutaneous malignancies, depression, and cervical dysplasia. No family members, in-
Ryan K. Orosco

Department of Otolaryngology-Head and Neck Surgery

Johns Hopkins Hospital

Baltimore, MD (USA)

E-Mail rorosco@ucsd.edu 
Fig. 1. Photograph of the African-American patient with XP demonstrating poikilodermatous skin changes with mottled hypo- and hyperpigmentation.
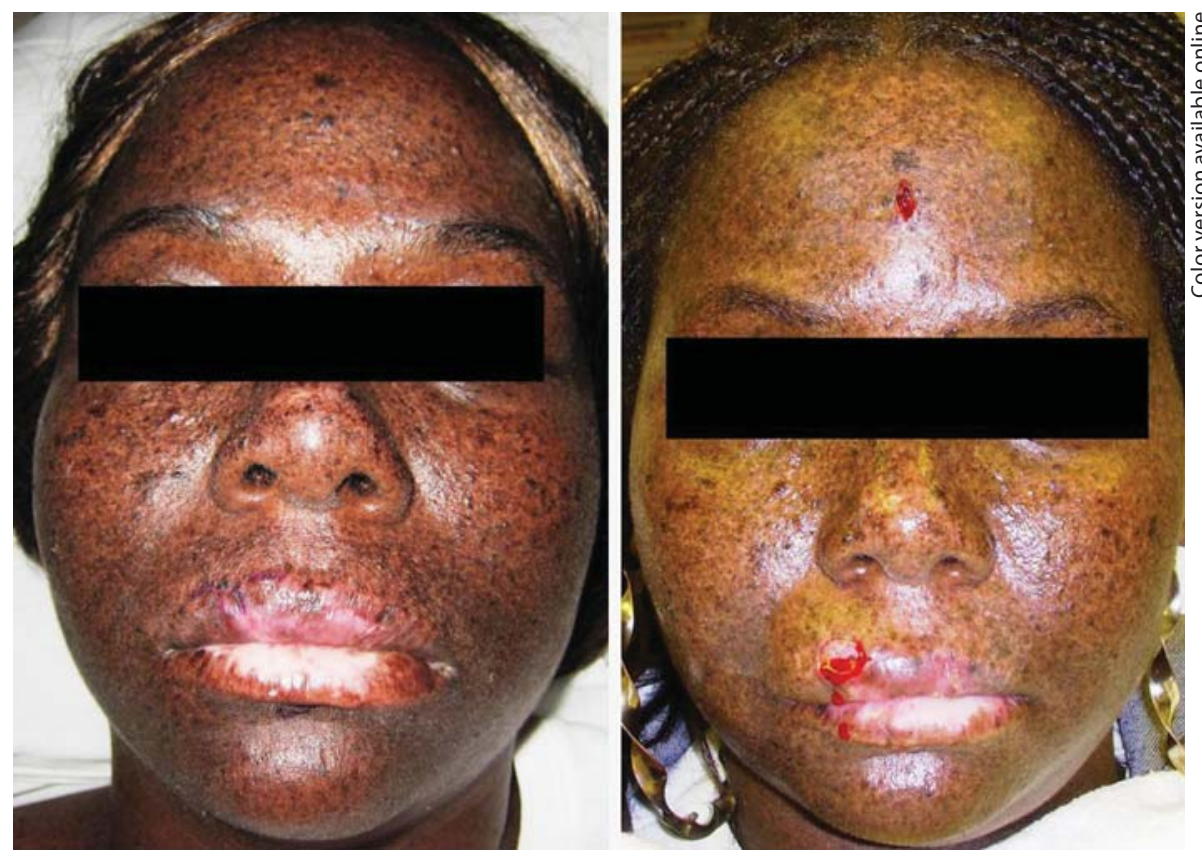

cluding her son, were affected by XP or had skin cancers, eczema, or psoriasis. There was no known family history of consanguinity. Physical examination was significant for poikilodermatous mottled hypo- and hyperpigmentation of sun-exposed skin with some sparing of the buttocks, scalp, abdomen, palms, and soles (fig. 1). There was atrophy of the tip of her tongue. Her nails were normal.

Her first cutaneous malignancy was a squamous cell carcinoma (SCC) of the lower eyelid, discovered at age 23 years. She had an SCC of the nose at age 26 years, and basal cell carcinomas (BCCs) on her right upper lid and chin were removed at age 31 years. One year later, she developed additional BCCs of left cheek and nasal fold. Most recently, she underwent excision of melanoma in situ on the forehead and another BCC on the chin/lip region. She is currently 34 years old.

\section{Discussion}

A review of the English literature was undertaken by searching the Embase and Medline databases using the keywords: 'xeroderma pigmentosum, African American, American, black'.

XP was described by Kaposi in 1870 and first reported in African blacks in 1938 [1]. Seven nucleotide excision repair mutations (XP-A through XP-G complement groups) and a post-replication repair defect (XPvariant) have been identified. These mutations in DNA repair manifest as cellular hypersensitivity to UV light and up to a 4,800-fold increased risk for cutaneous basal and squamous cell malignancies at age 20 years [2]. The incidence, disease phenotype, and population distribution vary among complement groups. The overall frequency in the USA and Europe is 1/250,000, with $\mathrm{XP}-\mathrm{C}$ and XP-A being the most common complement groups.

A recent study of XP patients in northern Africa reported a founder mutation in one of the DNA repair genes (XPC) [3]. This raises the possibility for XP genetic screening in certain high-risk ethnic groups likely to carry this mutation. The potential for early detection of XP would allow increased opportunities for primary preventive strategies in these high-risk patients. For the case presented herein, the specific XP mutation is not known, and her son could potentially carry her XP mutation. Therefore, he should similarly practice sun avoidance and primary prevention, and consultation with geneticists could be offered.

To the authors' knowledge, there have been 7 published cases of XP in African-American patients, the first in 1965 [4-7]. The initial report of Siegelman and Sutow [4] was of 2 siblings who developed exclusively BCC or SCC malignancies. They were followed only until ages 8 and 12 years, when one succumbed to metastatic SCC. Plotnick [5] reported 3 XP patients; 2 developed SCC of the tongue in early adolescence. Hananian and Cleaver 
[6] described a case of XP in a young girl with BCC, microcephaly, and systemic lupus erythematosus. Shao et al. [7] published the case of a 6-year-old boy who developed an atypical fibroxanthoma and 2 SCCs in the conjunctiva.

The most comprehensive review of XP patients included 830 cases from 297 articles, demonstrating a median age of first non-melanoma skin cancer of 8 years. Death occurred about 30 years earlier among XP patients than in the general US population, with a $90 \%$ probability of surviving to age 13 years and a $70 \%$ probability of surviving to age 40 years [2]. Two thirds of patients had affected relatives and consanguinity was present in $31 \%$. For the patients whose presence or absence of skin tumors was known (485 patients), malignant lesions were present in $78 \%$. Ocular involvement was seen in $40 \%$ of patients with appropriate data, $43 \%$ of whom had corneal abnormalities. Neurological and cognitive dysfunction have also been well reported in $\mathrm{XP}$ patients $[2,8]$.

Reports of XP in African patients describe aggressive courses with poor prognoses. In a recent case series of 12 African patients in Zimbabwe, XP appeared to present in a severe phenotype with an average age of first cutaneous malignancy of 4.6 years. The oldest survivor was followed until death at age 18 years. Cutaneous SCC was seen universally, tongue SCC in $92 \%$, ocular neoplasms in $8.3 \%$, and blindness in $83 \%$ [9]. Similarly, a case series of 15 black South Africans reported $80 \%$ cutaneous, $27 \%$ ocular, and 33\% tongue malignancy rates [10]. All 12 patients with cutaneous SCC developed their first lesion before the age of 6 years. In a Turkish case series of $12 \mathrm{XP}$ patients followed for 5 years, 9 developed SCC with a mean age at first appearance of 12 years [11].

$\mathrm{XP}$ has been shown to predispose patients to oral cancer, and even polymorphisms in XP genes may increase the risk of head and neck SCC $[12,13]$. The incidence of tongue SCC was higher in 2 African case series (92 and $33 \%)[9,10]$ than in one large meta-analysis of $830 \mathrm{XP}$ patients (1.6\%) [2]. This discrepancy in tongue malignancies may depend on UV exposure, comorbidities, and varying healthcare structures, but may also indicate increased susceptibility of African patients to tongue involvement. The tongue is generally protected from UV radiation, but it has been postulated that even minimal sun exposure to the tip during speaking, eating, and regular daily activity can lead to the malignancies seen in these patients [9]. Whether African-American XP patients carry a similarly heightened risk for tongue SCC is unknown, but notably in the case presented herein, hy- poplasia of the tip of the tongue was seen on physical examination. This prompts re-evaluation and potential further screening by biopsy or excision to monitor this patient for the development of tongue malignancy.

As with this patient, the most desirable approach in preventing cutaneous malignancy is aggressive sun avoidance techniques accompanied by the use of highSPF sunscreen. Additionally, we recommend avoidance of alcohol and tobacco. Systemic retinoids have also shown efficacy in the chemoprevention of non-melanoma skin cancer in these patients [14]. Once suspicious lesions develop, treatment options include cryotherapy, laser ablation, phototherapies, and surgical excision with the possible need for subsequent reconstructive procedures.

This case is the oldest reported surviving AfricanAmerican patient with XP. It highlights the ability of XP to present in this demographic with a diverse spectrum of malignancies and a potentially prolonged clinical course. The increased survival seen in this patient, compared to African counterparts, may result from a less severe nucleotide excision dysfunction caused by her XP mutation. Other factors that may contribute to her survival include: decreased UV exposure, SPF sun protection during exposure periods, early diagnosis, aggressive follow-up, and increased access to care.

In summary, we report a case of XP with a rare presentation in an African-American female with onset of cutaneous neoplasm in the third decade of life. She required multiple excisions for SCC, BCC, and melanoma lesions. The severe photosensitivity and increased incidence of malignancy seen in XP patients necessitate frequent surveillance with a low threshold for surgical and chemotherapeutic intervention. Future developments in early diagnosis, prevention, and treatment of cutaneous malignancies will be welcomed advances in the management of XP. 


\section{References}

$\checkmark 1$ Lowenthal L, Trowell H: Xeroderma pigmentosum in African Negroes. Br J Dermatol 1938;50:66-71.

2 Kraemer KH, Lee MM, Scotto J: Xeroderma pigmentosum: cutaneous, ocular, and neurologic abnormalities in 830 published cases. Arch Dermatol 1987;123:241-250.

3 Soufir N, Ged C, Bourillon A, Austerlitz F, Chemin C, Stary A, Armier J, et al: A prevalent mutation with founder effect in xeroderma pigmentosum group $\mathrm{C}$ from North Africa. J Invest Dermatol 2010;130:1537-1542.

$\checkmark 4$ Siegelman MH, Sutow WW: Xeroderma pigmentosum: report of 3 cases. J Pediatr 1965; 67:625-630.

5 Plotnick H: Xeroderma pigmentosum and mucocutaneous malignancies in three black siblings. Cutis 1980;25:311-313.
6 Hananian J, Cleaver JE: Xeroderma pigmentosum exhibiting neurological disorders and systemic lupus erythematosus. Clin Genet 1980;17:39-45.

7 Shao L, Newell B, Quintanilla N: Atypical fibroxanthoma and squamous cell carcinoma of the conjunctiva in xeroderma pigmentosum. Pediatr Dev Pathol 2007;10:149-152.

-8 Anttinen A, Koulu L, Nikoskelainen E, et al Neurological symptoms and natural course of xeroderma pigmentosum. Brain 2008;131 1979-1989.

-9 Chidzonga MM, Mahomva L, MakunikeMutasa R, Masanganise R: Xeroderma pigmentosum: a retrospective case series in Zimbabwe. J Oral Maxillofac Surg 2009;67: 22-31.

10 Jacyk WK: Xeroderma pigmentosum in black South Africans. Int J Dermatol 1999; 38:511-514.
11 Gül U, Kiliç A, Gönül M, Cakmak SK, Soylu S: Xeroderma pigmentosum: a Turkish case series. Int J Dermatol 2007;46:1125-1128.

12 Singh B, Shah JP: Skin cancers of the head and neck; in Shah JP (ed): Cancer of the Head and Neck, American Cancer Society, Atlas of Clinical Oncology. Hamilton, BC Decker, 2001, pp 77-80.

13 Shen H, Sturgis EM, Khan SG, Qiao Y, Shahlavi T, Eicher SA, Xu Y, et al: An intronic poly (AT) polymorphism of the DNA repair gene XPC and risk of squamous cell carcinoma of the head and neck: a case-control study. Cancer Res 2001;61:3321-3325.

14 Lens M, Medenica L: Systemic retinoids in chemoprevention of non-melanoma skin cancer. Expert Opin Pharmacother 2008;9: 1363-1374. 